Military Technical College

Kobry El-Kobbah, Cairo, Egypt

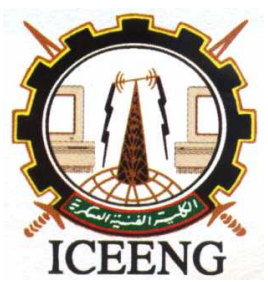

\author{
$6^{\text {th }}$ International Conference \\ on Electrical Engineering \\ ICEENG 2008
}

\title{
Coordinated design of power system stabilizers and static VAR compensators in a multi-machine power system using genetic algorithms
}

By
Omar H. Abdalla*
Wedad M. Refaey*
Mohamed K. Saad**
Gamal Sarhan**

\section{Abstract:}

This paper presents a procedure to coordinated design of Power System Stabilizers (PSSs) and Static VAR Compensators (SVCs) in a multimachine power system. The aims of the proposed method are to find the best location and the optimal parameters of these compensators in order to improve the steady state and transient performances and also to increase the system damping over a wide range of operating conditions. The objective function of the Genetic Algorithm (GA) allows the selection of the PSSs and SVCs to shift critical closed loop eigenvalues to the left side in the complex s-plane. The multimachine power system considered in this study consists of nine buses, three generating units (steam, hydro and nuclear) and three static loads. Digital simulation studies show that the proposed design procedure provides good damping for the power system at different operating conditions, and moreover improves steady-state and transient performance of the system.

\section{Keywords:}

Power System Stabilizer, Static VAR Compensator, Genetic Algorithm, Control, Eigenvalue Analysis, Stability.

* Faculty of Engineering, University of Helwan, Cairo, Egypt

** Benha High Technology Institute, Benha University, Egypt 


\section{Introduction:}

The design of Power System Stabilizers (PSSs) and Static VAR Compensators (SVCs) in multimachine power systems has found a considerable attention in recent decades. PSSs proved to enhance damping of electromechanical oscillations in electrical power systems [1-3]. Static VAR compensators [4-9] have proven to be very efficient to support both voltage and reactive power, and can be used to effectively improve both steady state and transient voltage performance [5]. Various control methods have been applied to design SVCs in power systems [10-15]. Application of adaptive control SVCs is presented in [10]. Robust control design of SVCs is investigated in [11] and [12]. Fuzzy logic control techniques are used in [13] and [14] to design SVCs controllers to improve power system stability. A genetic algorithm (GA) is employed in [15] to design an SVC control system.

This paper concerns with the application of GA to the design of PSSs and SVCs in a multimachine power system. The proposed genetic algorithm is employed to find the best location and optimal control parameters of the PSSs and SVCs in order to improve the steady state and transient performances. Also, it is required to increase the system damping over a wide range of operating conditions. The objective functions of the GA allow the selection of the PSS and SVC parameters to shift critical closed loop eigenvalues to the left side of a vertical line in the complex s-plane. PSS and SVC are designed and tested by computer simulation. Then, system performance with these controllers is investigated over a wide range of operating conditions and when it is subjected to various types of network disturbances.

The power system considered in this study consists of nine buses, three generating units and three loads. A full order nonlinear model is used to simulate the power system. A linear model is obtained by linearizing the system equations around a quiescent operating point for eigenvalue analysis. Digital simulation studies of the power system following various types of disturbances are performed to demonstrate the effectiveness of the selected PSS and SVC. The results show that the proposed PSS and SVC provide good damping for the power system at different operating conditions and moreover improve the transient and dynamic performance of the system. The GA is capable of accurately determining the best location and the optimal parameters of the PSS and SVC in the power system.

\section{System Modelling:}

The multimachine power system considered in this study consists of three generating units (steam at bus 1, hydro at bus 2 and nuclear at bus 3) interconnected through a transmission network and three constant impedance loads [16]. The one line diagram of 
the system is illustrated in Figure (1). Details of synchronous generator equations, representation of the turbines, speed governors, exciters, voltage regulators, and system parameter values can found in [17] and [18].

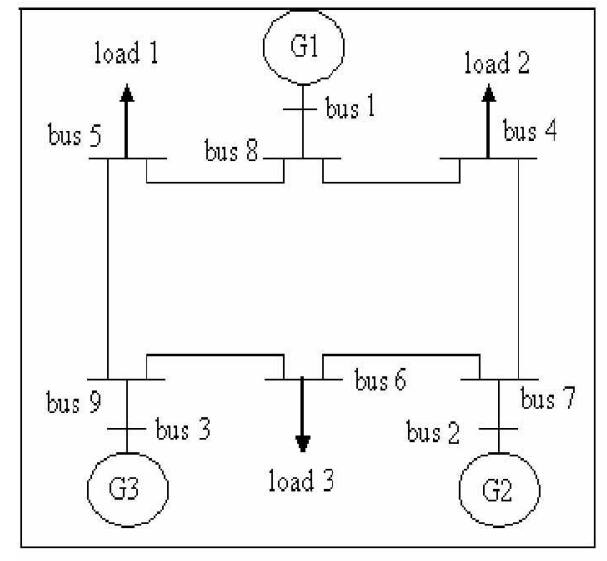

Figure (1): Power system

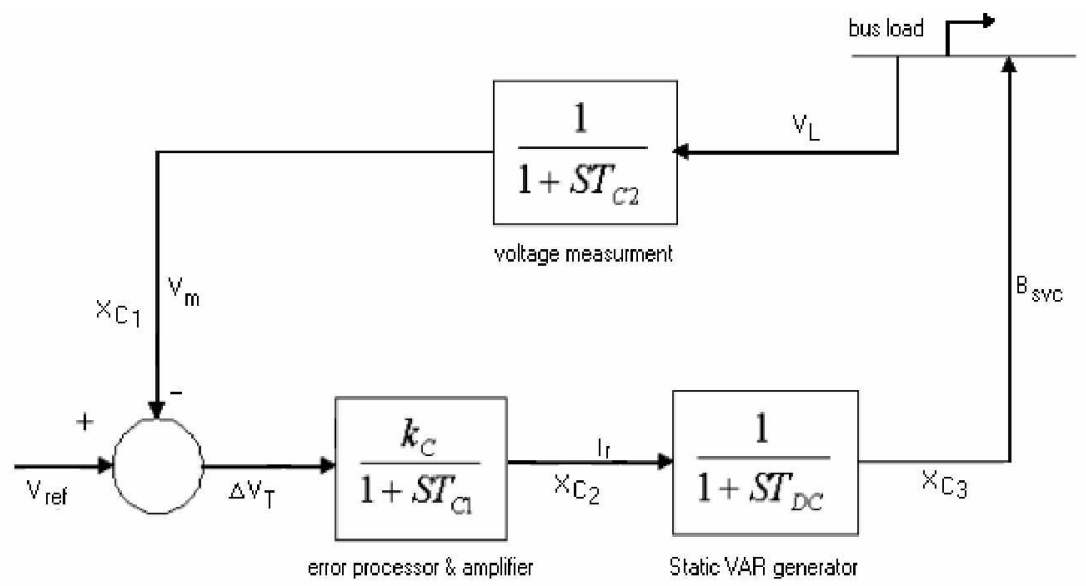

Figure (2): Block diagram of SVC

The PSS considered here is a speed stabilizer applied on the voltage regulator loop of the synchronous generator. A signal from the generator shaft speed is added through the PSS to the reference of the voltage regulator. The transfer function of the PSS is given in Eq. (1). It consists of a gain $K_{g}$, washout filter, and a lead-lag network.

$$
G(s)=K_{g} \frac{s T_{5}}{1+s T_{5}} \frac{\left(1+s T_{1}\right)\left(1+s T_{3}\right)}{\left(1+s T_{2}\right)\left(1+s T_{4}\right)}
$$

The SVC presented in this paper is of Fixed Capacitor Tyristor Controlled Reactor (FCTCR) type [19]. Figure (2) shows the block diagram of the SVC [20]. It can provide variable reactive current or susceptance $\mathrm{B}_{\mathrm{SVC}}$. When the voltage at load terminals decreases under the lower voltage limit (under voltage case) the SVC provides reactive power, or capacitive $B_{\mathrm{SVC}}$. When the voltage increases over the upper voltage limit (over voltage case) the SVC absorbs reactive power from the system, i.e. the $\mathrm{B}_{\mathrm{SVC}}$ becomes inductive. Thus, the closed loop SVC control system maintains constant voltage at the load busbar.

\section{Genetic Algorithm}

During the last decades there has been a growing interest in problem solving system based on principles of evolution and hereditary. The genetic algorithm is a type of 
evolution-based computer program to search for the fit solution of a particular problem [21-23]. Genetic algorithms are attractive techniques that employing natural evolution to solve problems in a wide field of complex applications. The GA is an iterative optimization technique, working with a number of candidate solutions (known as a population). If knowledge of the problem domain, is not available a priory, the GA begins its search from a random population of solutions [24]. A suitable coding (or representation) for the problem to be solved, must be defined first. In addition, a fitness function should be defined to assign a figure of merit to each coding solution. During the run, if the termination condition is not satisfied, parents must be selected for reproduction. Then, these are recombined to generate offspring using the reproduction, crossover and mutation operators to update the population of candidate solutions. Usually, a simple genetic algorithm consists of three operators: selection, crossover, and mutation. The application of these operations produces new strings (offspring), new population, and new generation, respectively. The overall process is then repeated with the new generation until the appropriate criterion is clearly satisfied.

\section{Problem Formulation}

\subsection{Eigenvalue analysis}

The nonlinear differential equations that describe the multimachine power system can be linearized about any particular operating point. A linearized model of the multimachine power system is obtained in the standard state-space form [18]:

$$
\dot{X}=A X+B U
$$

Where $X$ is the state vector, $U$ is the input vector, $A$ is the state coefficient matrix, and $B$ is the input coefficient matrix. The model can be derived by linearizing the nonlinear equations of the system (generators, exciters, automatic voltage regulator, speed governors, PSS and SVC). The components of $X$ and $U$ are the deviations of the variables from their corresponding steady-state values.

The eigenvalues of the matrix $A$ in Eq. (2) contain the necessary information on the small-signal stability of the multimachine system [18]. The system is stable if all the eigenvalues lie on the left-hand side of the s-plane. The real eigenvalues are related to exponential components in the time response. The complex conjugate pairs of eigenvalues are associated with the oscillatory modes in the time response. They have the form:

$$
\lambda=-\alpha \pm j \beta
$$

$\beta$ gives the frequency of the oscillations in $\mathrm{rad} / \mathrm{sec}$ and the value of $1 / \alpha$ defines the 
time constant by which the magnitude of the oscillation is decayed. Studies of the effects of changes in operating conditions and system parameters lead to the identification of the eigenvalues which may cause instability. The most important eigenvalues are those related to rotor oscillations. In this case the eigenvalues are constrained to lie to the left of a vertical line corresponding to a specified damping ratio.

\subsection{Selection of PSS and SVC}

The problem is to design suitable PSS and SVC controllers for the multimachine power system. The goals of this approach are to provide voltage and reactive power support and to improve the damping of system oscillations by selecting the best location and parameter values of the PSS and SVC controllers.

First, we design the required PSS for the power system using GA techniques. The objective functions of GA and eigenvalue analysis allow determining the best location and selecting the optimal parameters of PSS. Then, the SVC is designed using the same design procedure. The performances of the power system with both PSS and SVC are investigated over wide operating conditions and various types of network disturbances.

\section{Design Procedure}

The search of any genetic algorithm starts with a random generation of a population of strings. Each generation consists of a group of population. Also, each population consists of a group of strings. The number of strings in a population must be even. Each string is divided into a number of sub-strings equal to the number of the problem variables. Each sub-string consists of a number of genes to represent one of the variables in a certain coding system. Floating point, decimal point, and binary coding systems could be used. In this study, the binary coding system is used. Evaluation of each string in the population is performed by using the fitness function which maps the problem objective function.

The GA selects the optimal location and parameters of the PSS by shifting eigenvalues of the matrix A to the left hand side. The objective function (O. F.) which is used in the genetic algorithm can be written as:

O. F. $=-$ Real $\{$ dominant eigenvalues $\}$

The optimization problem, namely, the selection of parameters and location of compensators is readily and accurately solved using the genetic algorithms. The eigenvalues of the closed loop system are computed, and the objective function is 
evaluated using only those eigenvalues that need to be shifted. In a typical run of the $\mathrm{GA}$, an initial population is randomly generated.

This initial population is referred to as the 0th generation. Each individual in the initial population has an associated objective function value. Using the objective function information, the GA then produces a new population. The GA calculates the value of objective function for each of the individuals in the current population. To do this the system eigenvalues must be computed.

The GA then produces the next generation of individuals using the selection crossover and mutation operators. These steps are repeated from generation to generation until the population has converged producing the optimum location and optimum parameters of the PSS.

The design procedure is repeated to select the appropriate SVC for the multimachine power system. Now, the objective is to find the best location and the optimal parameters of the static VAR compensators, assuming no PSS.

\section{Simulation Results}

Simulation results are presented to illustrate the effectiveness of the proposed GA based PSS and SVC in the power system under different operating points and different disturbances such as load change, line opening, and three phase short circuit. Three operating points are considered as shown in Table (1). The first stage in the digital simulation of the multimachine power system is to obtain complete information on the network. The information comprises the magnitude and phase angle of the bus voltages and real and reactive power.

Table (1): Operating points

\begin{tabular}{|c|c|c|c|}
\hline Item & $\begin{array}{c}\text { Operating } \\
\text { point } \mathbf{1}\end{array}$ & $\begin{array}{c}\text { Operating } \\
\text { point 2 }\end{array}$ & $\begin{array}{c}\text { Operating } \\
\text { point 3 }\end{array}$ \\
\hline $\mathbf{V}_{\mathbf{t} \mathbf{1}}(\mathrm{pu})$ & 1.04 & 1 & 1 \\
\hline $\mathbf{V}_{\mathbf{t} 2}(\mathrm{pu})$ & 1.012 & 1.012 & 1 \\
\hline $\mathbf{V}_{\mathbf{t} \mathbf{3}}(\mathrm{pu})$ & 1.022 & 1.022 & 1 \\
\hline $\mathbf{P}_{\mathbf{2}}(\mathrm{pu})$ & 1.63 & 1.75 & 1.63 \\
\hline $\mathbf{P}_{\mathbf{3}}(\mathrm{pu})$ & 0.85 & 0.75 & 0.85 \\
\hline
\end{tabular}


To determine the complete nodal information of the network, the Gauss Siedel load flow method is used. Table (2) shows the initial values of the generators variables at the operating point 1.

Table (2): Initial values at operating point 1

\begin{tabular}{|c|c|c|c|}
\hline Quantity (PU) & Generator 1 & Generator 2 & Generator 3 \\
\hline $\mathbf{P}$ & 0.717 & 1.63 & 0.85 \\
\hline $\mathbf{Q}$ & 0.316 & 0.008 & 0.076 \\
\hline \hline $\mathbf{V}_{\mathbf{t}}$ & 1.040 & 1.012 & 1.022 \\
\hline $\mathbf{V}_{\mathbf{d}}$ & 0.646 & 0.960 & 0.913 \\
\hline $\mathbf{V}_{\mathbf{q}}$ & 0.814 & 0.32 & 0.46 \\
\hline $\mathbf{I}_{\mathbf{d}}$ & 0.667 & 1.530 & 0.709 \\
\hline $\mathbf{I}_{\mathbf{q}}$ & 0.352 & 0.503 & 0.441 \\
\hline
\end{tabular}

The GA has selected the optimal location of the PSS to be at load bus 2, and finds its optimal parameters values. It is assumed that $T_{2}=T_{4}=0.05 \mathrm{~s}$ and $T_{5}=10 \mathrm{~s}$, the values of the remaining PSS parameters $\left(K_{g}, T_{1}\right.$ and $\left.T_{3}\right)$ are to be optimized by the genetic algorithm. The GA design procedure described in Section 5 is employed.

The small signal stability of the power system is investigated by eigenvalue analysis. The system eigenvalues are calculated and dominant ones are listed in Table (3). It is seen that the introduction of a PSS at bus 2 significantly improves the system damping. The linearized model studies are also supported by simulation of the non-linear model when the system is subjected to various types of disturbances.

Table (3): Dominant eigenvalues with PSS

\begin{tabular}{|c|c|c||c|}
\hline PSS Location & $\begin{array}{c}\text { Operating } \\
\text { point 1 }\end{array}$ & $\begin{array}{c}\text { Operating } \\
\text { point 2 }\end{array}$ & $\begin{array}{c}\text { Operating } \\
\text { point 3 }\end{array}$ \\
\hline Without PSS & $-0.8845 \pm \mathrm{j} 2.0389$ & $-1.0904 \pm \mathrm{j} 2.0268$ & $-0.8563 \pm \mathrm{j} 1.8451$ \\
\hline PSS at bus 1 & $-1.1318 \pm \mathrm{j} 1.9039$ & $-1.2327 \pm \mathrm{j} 1.7952$ & $-0.9889 \pm \mathrm{j} 1.7452$ \\
\hline \hline PSS at bus 2 & $-\mathbf{- 4 . 8 5 6 0} \pm \mathbf{j} 2.8550$ & $-\mathbf{4 . 8 9 2 2} \pm \mathbf{j 3 . 9 0 0 5}$ & $\mathbf{- 5 . 4 2 3 1} \pm \mathbf{j 3 . 7 9 3 8}$ \\
\hline PSS at bus 3 & $-1.2670 \pm \mathrm{j} 1.3960$ & $-2.0199 \pm \mathrm{j} 1.3659$ & $-2.3007 \pm \mathrm{j} 1.6534$ \\
\hline
\end{tabular}


Table (4) shows the effect of the static VAR compensator on the system damping. The GA selects the optimal location of the SVC to be at load bus 4 and finds the optimal parameters $\left(K_{C}, T_{C 1}\right.$ and $\left.T_{C 2}\right)$ of the SVC. Bus 4 is heavily loaded compared to other buses in the system and has the lowest voltage level. In addition to support voltage and reactive power the SVC at bus 4 provides good damping as shown from the real parts of the dominant eigenvalues listed in the table. It is also noted that the well tuned SVC significantly improves the damping at the three different operating points considered here. In the results of Table (4) the PSS is excluded to concentrate on the effect of the SVC. MATLAB is used in GA and eigenvalue simulation studies.

Now, the PSS and the SVC are applied to the power system simultaneously. The PSS is located at bus 2, and the CVS at load bus 4 . The system performance is investigated when it is subjected to various disturbances at different operating conditions. In the simulation studies, we use the full order nonlinear model of the complete power system. The nonlinear differential equations of each machine are solved using the $4^{\text {th }}$-order Rung Kutta technique for a step of integration equal to $0.1 \mathrm{~ms}$. Then, the currents $I_{d}$ and $I_{q}$ of each machine are calculated with respect to the machine reference frame by using the states which are obtained from the integration of the differential equations. Next, the machine voltages $\mathrm{V}_{\mathrm{d}}$ and $\mathrm{V}_{\mathrm{q}}$ are computed through the common reference machine. Machine 1 is selected as a reference machine. Finally, the results are used to process the next step of integration. This process is continued until we reach the final simulation time which is 5 $\mathrm{s}$ in this study. Q-basic was used in load flow and non-linear simulation studies.

Figure (4) shows the system responses to $10 \%$ sudden increases in demanded active and reactive powers at bus 5 at operating point 1 . Figure (5) shows the system response to $10 \%$ sudden decrease in the load power at bus 4 at operating point 2 . Figure (6) shows the system response to a line outage between buses 4 and 7 at operating point 3 . Figure (7) shows the system response to a three phase fault at bus 5 at operating point 1.

Table (4): Dominant eigenvalues with SVC

\begin{tabular}{|c|c|c||c|}
\hline SVC Location & $\begin{array}{c}\text { Operating } \\
\text { point 1 }\end{array}$ & $\begin{array}{c}\text { Operating } \\
\text { point 2 }\end{array}$ & $\begin{array}{c}\text { Operating } \\
\text { point 3 }\end{array}$ \\
\hline Without SVC & $-0.8845 \pm \mathrm{j} 2.0389$ & $-1.0904 \pm \mathrm{j} 2.0268$ & $-0.8563 \pm \mathrm{j} 1.8451$ \\
\hline SVC at bus 4 & $-\mathbf{2 . 5 8 9 0} \pm \mathbf{j} 2.0936$ & $-\mathbf{2 . 9 8 1 7} \pm \mathbf{j 2 . 1 5 5}$ & $-\mathbf{2 . 7 8 9 4} \pm \mathbf{j} 2.1102$ \\
\hline SVC at bus 5 & $-0.9718 \pm \mathrm{j} 1.9365$ & $-1.3346 \pm \mathrm{j} 1.1794$ & $-1.0648 \pm \mathrm{j} 0.9306$ \\
\hline SVC at bus 6 & $-1.2372 \pm \mathrm{j} 1.0453$ & $-2.9957 \pm \mathrm{j} 2.5156$ & $-2.103 \pm \mathrm{j} 1.6839$ \\
\hline
\end{tabular}




\section{Conclusions:}

This research has described an artificial intelligence method to design power system stabilizers and static VAR compensators in a multimachine power system. This method is based on a genetic algorithm technique. The genetic algorithm method has been used to select the best location and optimal parameters of the PSS and SVC. The objective functions allow the selection of the parameters to shift critical closed loop eigenvalues to the left hand side of a vertical line in the complex s-plane. The GA selects the best location of the PSS to be at the generator bus 2 and the SVC at load bus 4 in the multimachine power system considered here. The simulation results have shown that the selected PSS and SVC are capable of providing sufficient damping to the system oscillation and improving the steady state and transient voltages performance over a wide range of operating conditions and various types of disturbances.
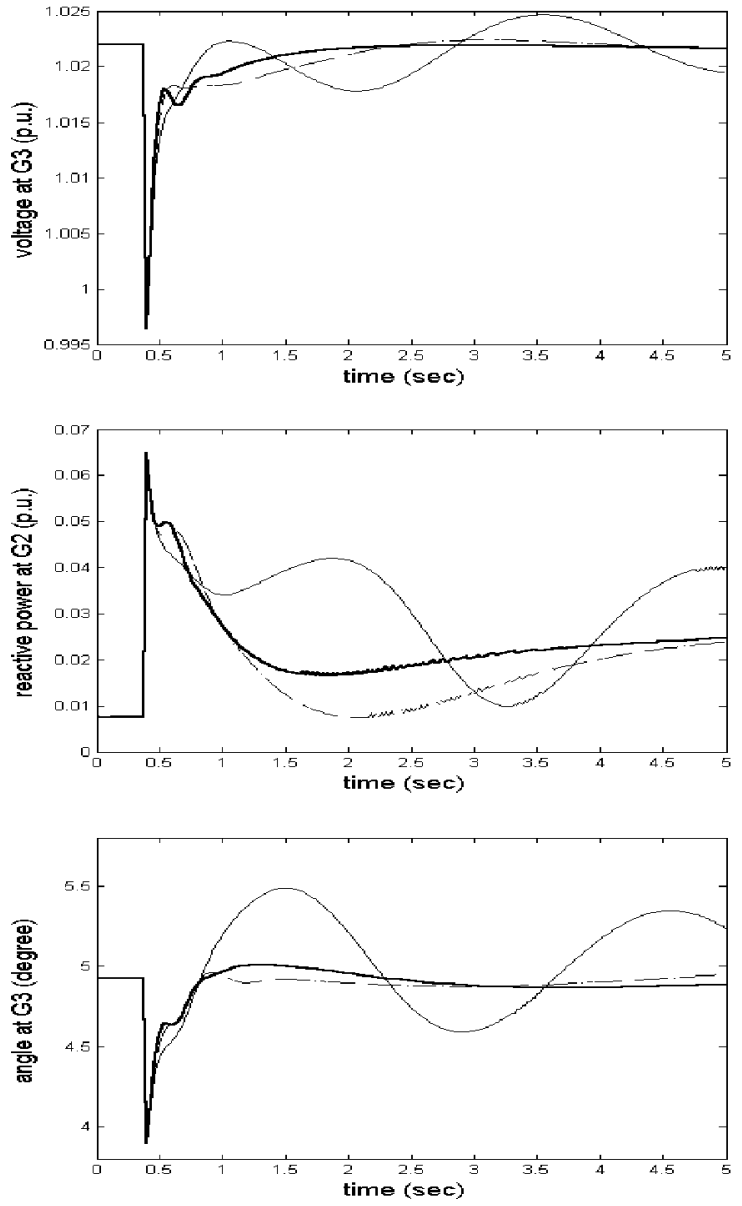

Figure (4): System response to $10 \%$ sudden increases in load power at bus 5 at operating point 1 .
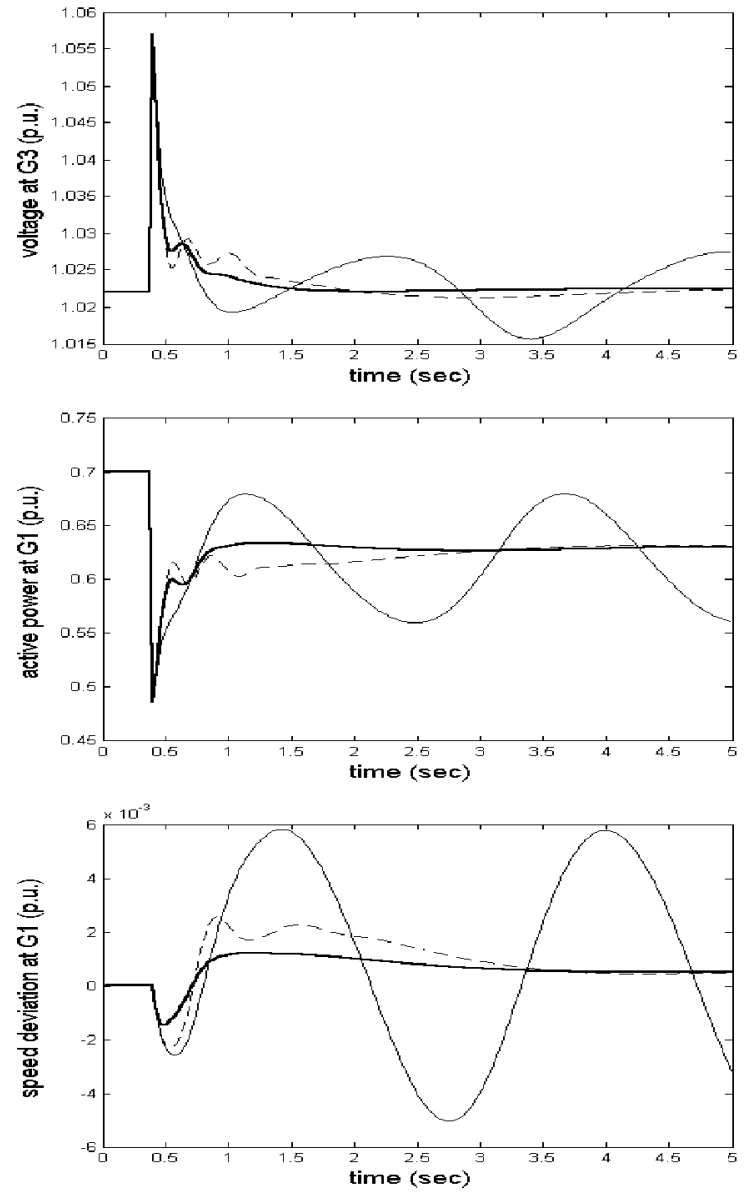

Figure (5): System response to $10 \%$ sudden decrease in load power at bus 4 at operating point 2 . 

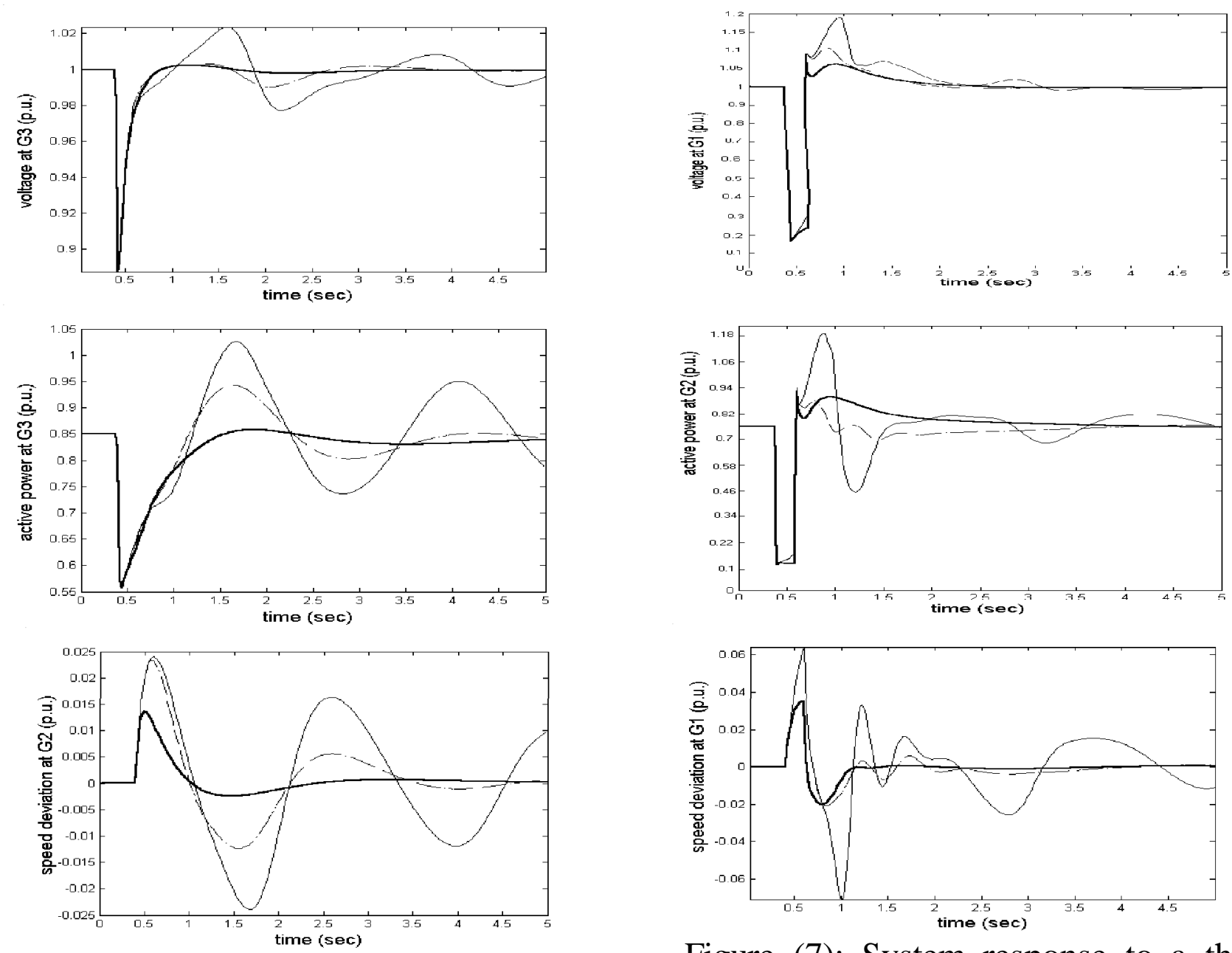

Figure (7): System response to a three

Figure (6): System response to a complete line outage between buses $4 \& 7$ at operating point 3 . phase fault for $120 \mathrm{~ms}$ at bus 5 at operating point 2 .

The following notations have been used in the results shown in Figures (4) to (7).

- Without PSS \& SVC

-.... With PSS on bus 2

With PSS on bus $2 \&$ SVC on bus 4

\section{References:}

[1] E. V. Larsen and D. A. Swann, Applying Power System Stabilizers, Parts I-III, IEEE Transactions on Power Apparatus and Systems, Vol. PAS-100, No. 6, pp. 3017-3046, June 1981. 
[2] Y. Y. Hsu and K. L. Lious, Design of Self Tuning PID Power System Stabilizer for Synchronous Generators, IEEE Transactons on Energy Conversion, Vol. 2, No. 3, pp. 343-348, 1987.

[3] S. Chen and O. P. Malik, Power System Stabilizer Design Using $\mu$ Synthesis, IEEE Transactions on Energy Conversion, Vol. 10, No. 1, pp. 175-181, 1995.

[4] A. E. Hammad, Analysis of Power System Stability Enhancement by Static VAR Compensators, IEEE Transactions on Power Systems, Vol. 1, No. 4, pp. 222-227, 1986.

[5] E. Z. Zhou, Applications of Static VAR Compensators to Increase Power System Damping, IEEE Transactions on Power Systems Vol. 8, No. 2, pp. 655-661, 1993.

[6] H. F. Wang and F. I. Swift, Capability of the Static VAR Compensator in Damping Power System Oscillations, Proceedings IEE Part C, Generation, Transmission \& Distribution, Vol. 143, No. 4, pp. 353-358, 1996.

[7] A. R. Messina, O. Begovich and M. Nayebzadeh, Analytical Investigation of Use of Static VAR Compensators to Aid Damping of Interarea Oscillations, Electric Power System Research, Vol. 51, pp. 199-210, 1999.

[8] X. Yu, M. Khammash and V. Vittal, Robust Design of a Damping Controller for Static VAR Compensators in Power Systems, IEEE Transactions on Power Systems, Vol. 16, No. 3, pp. 456-462, 2001.

[9] F. Puorboghrat et al, Local Sliding Control for Damping Interarea Power Oscillations, IEEE Transactions on Power Systems, Vol. 19, No. 2, pp. 1123-1134, 2004.

[10] P. K. Dash et al, Adaptive Controller for Static Reactive Power Compensators in Power Systems, Proceedings IEE, Part C, Generation, Transmission \& Distribution, Vol. 134, No. 3, pp. 256-264, 1987.

[11] Q. Zhao and J. Jiang, Robust SVC Controller Design for Improving Power System Damping, IEEE Transactions on Power Systems, Vol. 10, No. 9, pp. 1927-1932, 1995.

[12] M. Parniani and M. R. Irvani, Optimal Robust Control Design of Static VAR Compensators, Proceedings IEE, Part C, Generation, Transmission \& Distribution, Vol. 145, No. 3, pp. 301-307, 1998.

[13] P. K. Dash, S. Mishra and A. C. Liew, Fuzzy Logic Based VAR Stabilizer for Power System Control, Proceedings IEE, Part C, Generation, Transmission \& Distribution, Vol. 142, No. 6, pp. 618-624, 1995.

[14] K. L. Lo and M. O. Sadegh, Systematic Method for the Design of a Full-Scale Fuzzy PID Controller for SVC to Control Power System Stability, Proceedings IEE, Part C, Generation, Transmission \& Distribution, Vol. 150, No. 3, pp. 297-304, 2003. 
[15] P. Ju, E. Handschin and F. Reyer, Genetic Algorithm Aided Controller Design with Application to SVC", Proceedings IEE, Part C, Generation, Transmission \& Distribution, Vol. 143, No. 3, pp. 258-262, 1996.

[16] A. A. Nour-Eldeen, W. M. Refaey and O. H. Abdalla, Identification and Static VAR Control of a Multimachine Power System, Proceedings of the Fifth International Middle East Power Systems Conference MEPCON'97, pp. 17341740, 1997.

[17] P. M. Anderson and A. A. Fouad, Power System Control and Stability, Iowa State University Press, 1977.

[18] O. H. Abdalla, S. A. Hassan, and N. T. Tweig, Coordinated Stabilization of a Multimachine Power System, IEEE Transactions on Power Apparatus and Systems, Vol. PAS-103, No. 3, pp. 483-493, 1984.

[19] R. T. Byerly, D. T. Penmariak and E. R. Taylor, Static Reactive Compensation for Power Transmission Systems, IEEE Transactions on Power Apparatus and Systems, Vol. PAS-101, No. 10, pp. 3997-4006, 1982.

[20] H. A. Perez, E. Acha, and C. R. Fuerte, Advanced SVC Models for Newton Raphson Load Flow and Newton Optimal Power Flow Studies, IEEE Transactions on Power Systems, Vol. 15, No. 1, pp. 129-136, 2000.

[21] D. E. Goldberg, Genetic Algorithms in Search, Optimization, and Machine Learning, Addison-Wesley, 1989.

[22] D. E. Goldberg, Genetic and Evolutionary Algorithms Come of Age, Communications of the ACM, Vol. 37, No. 3, pp. 113-119, 1994.

[23] Z. Michalewicz, Genetic Algorithms + Data Structure = Evolutionary Programs, Springer-Verag, Berlin Heidelberg, 1996.

[24] D. Dracopoulos, Genetic Algorithms and Genetic Programming for Control, In Dasgupta and Michalewicz (eds.), Evolutionary Algorithms in Engineering Applications, Spriger-Verlag, 1997.

\section{Nomenclatures:}

$\mathrm{K}_{\mathrm{C}}$, and $\mathrm{T}_{\mathrm{C} 1}, \mathrm{~T}_{\mathrm{C} 2}, \mathrm{~T}_{\mathrm{DC}}$

$\mathrm{X}_{\mathrm{C} 1}, \mathrm{X}_{\mathrm{C} 2}, \mathrm{X}_{\mathrm{C} 3}$

$\mathrm{V}_{\text {ref }}$

$\mathrm{K}_{\mathrm{g}}$ and $\mathrm{T}_{1}, \mathrm{~T}_{2}, \mathrm{~T}_{3}, \mathrm{~T}_{4}, \mathrm{~T}_{5}$

$\mathrm{P}, \mathrm{Q}$

$\mathrm{V}_{\mathrm{t}}, \mathrm{V}_{\mathrm{L}}$

$\mathrm{V}_{\mathrm{d}}, \mathrm{V}_{\mathrm{q}}$

$\mathrm{I}_{\mathrm{d}}, \mathrm{I}_{\mathrm{q}}$
Gain and time constants of SVC

State variables of SVC

Reference voltage

Gain and time constants of PSS

Active, reactive powers

Generator terminals' voltage, load voltage

d-axis, q-axis voltages

d-axis, q-axis currents 